\title{
CHARCOAL BEFORE THE WAR. I
}

BY, WILDER D. BANCROFT

When carbonaceous material is heated or otherwise decomposed in the absence of air or in the presence of insufficient air to cause complete combustion, a porous, carbonized or charred product is obtained which is known as charcoal. Charcoal is often called by different names, varying with the material from which it is made. Thus we have wood charcoal, bone charcoal, blood charcoal, sugar charcoal, and gas charcoal. Charcoal made from gaseous material may also be called soot, lamp-black, carbon black, and gas carbon; though this last term is also used to denote carbon from the blast furnace. Charcoal from coal is usually called coke and is ordinarily not considered as charcoal though it comes under the definition. Graphite is usually not classed as charcoal though it is really a limiting case: Another differentiation is into vegetable, animal, and mineral charcoal, where mineral charcoal certainly includes coke and may include the gas charcoals. The two properties of charcoal which interest us are the power of adsorbing or condensing gases in the pores and the power of extracting coloring matter and other substances from solution. This property of wood charcoal was discovered by Löwitz in 1790 and was made use of in the refining of sugar until a pharmacist named Fiquier showed in I 8 I I that animal charcoal was an even more effective decolorizing agent. In the following year, Derosne employed animal charcoal for the treatment of beet juice in the place of wood charcoal, which had been used for this purpose in France since the beginning of the beet sugar industry there.

Wood charcoal is made by burning or distilling wood in stacks, in pits, in closed chambers of brick or stone, or in iron retorts. The yield of charcoal will vary with the kind of wood, the temperature at which it is charred and the amount of air which is admitted. The yield of charcoal is less, the higher the temperature. Violette ${ }^{1}$ obtained yields of $50 \%$

\footnotetext{
${ }_{1}$ Comptes rendus, 32, 713 (1851); 38, I07 (1854).
} 
at $250^{\circ}, 33 \%$ at $300^{\circ}, 20 \%$ at $400^{\circ}$, and $15 \%$ at $1500^{\circ}$, the highest temperature that could be reached. These' temperatures are not to be considered as accurate. At constant temperature the amount of charcoal is greater the longer the time of carbonization. Thus, very slow charring at $400^{\circ}$ gave twice as much charcoal as very rapid charring did. At $250^{\circ}$ the charcoal contained about $65 \%$ carbon, this figure rising to $73 \%$ at $300^{\circ}, 80 \%$ at $400^{\circ}$, and about $96 \%$ at $\mathrm{I} 500^{\circ}$. When wood is charred in a completely closed vessel the yield of charcoal is much greater because much of the volatile carbonaceous matter is decomposed. When heated to $300^{\circ}-$ $400^{\circ}$ in an absolutely closed vessel, wood seems to melt and flow, sticking to the walls. When cooled, the mass has no structure and forms a black glistening mass like tar, containing about $67 \%$ carbon and $27 \%$ oxygen, the unstated balance being probably ash and hydrogen.

Charcoal made in kilns is not homogeneous. It may contain $73 \%$ carbon near the outside of the kiln and $85 \%$ at the center where it has been heated more. When wood is charred in superheated steam, the product is more uniform and can be controlled better. Thus, it is quite simple to get a reddish charcoal containing $70 \%$ carbon or a very black charcoal with $88 \%$ carbon. Wood charcoal made at $280^{\circ}$ is friable, reddish, and inflammable. When made at $1000^{\circ}-$ $1500^{\circ}$ it is very black, very dense, and very slightly inflammable. When heated to the melting point of platinum, it is hard to break, gives a sonorous ring like a metal when struck, burns with difficulty, and can be heated red-hot in a flame, like iron.

The amount of ash in wood charcoal varies with the nature of the wood; but is ordinarily between one and three percent. Berthelot ${ }^{1}$ analyzed one sample containing $\mathrm{I} .6 \mathrm{I} \%$ ash and found the ash to consist of $\mathrm{SiO}_{2}, 0.083 ; \mathrm{CaO}, 0.679 ; \mathrm{K}_{2} \mathrm{O}$, 0.I56; iron, alumina, mineral acids, etc., 0.792 .

Foster ${ }^{2}$ has determined the amount of carbon and hydro-

${ }_{1}$ Comptes rendus, I4I, 793 (1905).

2 Proc. Chem. Soc., 1892, 46. 
gen in charcoals obtained by carbonizing sugar and starch, getting the following results:

\begin{tabular}{|c|c|c|c|}
\hline & $\mathrm{c}$ & $\mathrm{H}$ & \\
\hline Sugar & 95.0 & I. I & High temperature \\
\hline Sugar & $94 . I$ & I. 2 & Low temperature \\
\hline Starch & 95.0 & 0.9 & \\
\hline
\end{tabular}

Cross and Bevan ${ }^{1}$ lay stress on the fact that charcoal is not, strictly speaking, a form of carbon, and that sulphuric acid does not convert sugar into carbon and water. They propose the term pseudo-carbons for the black substances, containing a more or less high percentage of carbon, which are formed by the charring of carbonaceous compounds either by the action of heat or otherwise.

Carbon black ${ }^{2}$ is the soot produced when a flame of natural gas burning with insufficient air impinges against the lower surface of an iron plate. The yield is very low, not over one pound per rooo cu. ft. of gas. All carbon blacks have a general family resemblance, being very intense in color, and glossy whether rubbed in the dry or in varnish. When pure, they mix readily with water; but traces of oily matter prevent this. It is said that there is a difference in this respect between carbon black and lamp-black which is the soot from oils; but this is not a real distinction. Lamp-black is usually dirtier than carbon black and consequently is wetted less readily; but it is merely a question of degree of purification. Carbon black is an extremely light, fine powder, weighing less than five pounds to the cubic foot and it will sometimes oscillate in waves, almost like water, owing to the large amount of air in the mass. It is easily electrified and flies up in the air if a piece of sealing-wax is rubbed over the sleeve and then passed over the black. To compress carbon black it is necessary to let the air escape without carrying the black with it. This

\footnotetext{
1 Phil. Mag., [5] 13, 325 (1882).

${ }^{2}$ Cabot: Jour. Soc. Chem. Ind., I3, I28 (1894); Int. Congress Applied Chemistry, New York, I2, I8 (1912).
} 
can be done by covering the plunger of the press with a sheepskin, woolly side out. The wool retains the black but lets the air pass through.

It is claimed by Frank ${ }^{1}$ that if acetylene is mixed with carbon monoxide or dioxide and decomposed by explosion, the carbon of both gases is deposited in a pure form, free from tarry condensation products, according to the equation $\mathrm{C}_{2} \mathrm{H}_{2}+$ $\mathrm{CO}={ }_{3} \mathrm{C}+\mathrm{H}_{2} \mathrm{O}$. The carbon black so obtained is said to be superior to the best American carbon black in color and covering power. If carbon monoxide or carbon dioxide be allowed to act on carbides of the alkalies or alkaline earths at a high temperature, the carbon comes out as graphite, the reaction being represented by the equation $\mathrm{CaC}_{2}+\mathrm{CO}={ }_{3} \mathrm{C}+$ $\mathrm{CaO}$.

Morehead $^{2}$ has patented the preparation of carbon black from a gaseous mixture of acetylene and oxygen or air, the proportion of air being above 1 percent, and preferably about 4.5 percent. The mixture is compressed, passed into a vacuous explosion vessel, and exploded, the minimum pressure required to effect dissociation being used, namely, about $60 \mathrm{lbs}$. per square inch. The resulting carbon is removed from the explosion vessel by an air-blast.

Mixter ${ }^{3}$ has studied the carbon which separates when acetylene under pressure is exploded. As it comes from the bomb it is a grayish black, lusterless, and very bulky, porous mass. When compressed it has a brilliant black luster, but not the metallic appearance of graphite. It is not graphite and does not contain graphite and yet the heat of combustion of 12 grams is 94,728 calories which is fairly close to the value of 94,000 calories for graphite and considerably less than the value of 96,500 calories for sugar charcoal and gas-retort carbon. Mixter considers that this is a special allotropic form of carbon; but it is quite possible that it is a very pure form of carbon be-

${ }^{1}$ Jour. Soc. Chem. Ind., 24, I I 77 (1905).

${ }^{2}$ U. S. Pat. 779,728 (1905).

${ }^{3}$ Am. Jour. Sci., [4] 19, 434 (1 905). 
cause Mixter gives its composition as $99.95 \%$ carbon and $0.03 \%$ hydrogen.

When pure acetylene ${ }^{1}$ is passed over copper foil at $250^{\circ}$ or over reduced, pulverulent copper at about $180^{\circ}$, the gas is absorbed at first without apparent change in the structure of the copper, while hydrocarbons of the ethylene series condense in the cooler parts of the tube. After absorption is nearly complete, the copper begins to swell very considerably in bulk, the color becoming lighter, and the condensing liquids changing to a mixture of ethylene and aromatic hydrocarbons, while the escaping gas consists chiefly of a mixture of ethylene hydrocarbons with some ethane and hydrogen, and a little acetylene. The solid finally becomes a soft, light or dark yellow, substance, composed of matted filaments. When compressed gently, it resembles touch-wood. It burns in air with a smoky flame and an aromatic odor, and leaves a slight residue of copper oxide. It is a hydrocarbon of unknown molecular weight and apparently having the empirical formula $\mathrm{C}_{7} \mathrm{H}_{6}$, corresponding to about $92.3 \%$ carbon. The name "cuprene" has been suggested for it.

Moissan" points out that amorphous charcoals always contain hydrogen and are likely to contain traces of iodine, lead, zinc, iron, etc., depending on the way in which they are made. They retain water quite firmly and the true density varies apparently between $I .76$ and $\mathrm{I} .87$. The higher the temperature at which the charcoal has been prepared, or to which it has been heated, the less readily does it burn in oxygen, the ignition temperatures as determined varying from $370^{\circ}$ to $506^{\circ}$. It also becomes less readily attacked by a mixture of potassium bichromate and sulphuric acid. The changes take place slowly at each temperature. The amorphous charcoals prepared by Moissan usually contained about $93 \%$ carbon, the remainder being presumably ash, hydrogen, and water. The lower the temperature at which the charcoal is prepared, the more nearly brown the color is rather than black.

'Sabatier and Senderens: Comptes rendus, I30, 250 (1900).

"Ann. Chim. Phys., [7] 8, 289 (1896). 
Black, amorphous carbon, prepared from any form of organic matter by destructive distillation or imperfect combustion, always retains small amounts of hydrogen, oxygen, or nitrogen (if nitrogenous matter be used). One of Mallet's students, ${ }^{1}$ therefore, attempted to prepare charcoal from. material absolutely free from these elements. Metallic sodium was freed very carefully from any traces of naphtha and was placed in a hard-glass tube from which all the air was driven by carbon tetrachloride vapor, after which the sodium was. heated in presence of a current of carbon tetrachloride. In order to protect the glass, the sodium was placed at first on a layer of pure, well-burned lime. The violence of the reaction caused some volatilization of the sodium, however, and the upper part of the glass tube was attacked, introducing silicon into the product. To avoid this the lime was placed later in a loose inner tube of copper foil, platinum having proved unsatisfactory. The carbon always contained some calcium and some copper, which had to be removed by prolonged treatment with nitric and hydrochloric acids, followed by washing with water. After much difficulty a specimen was obtained finally which was almost free from ash. To drive off gases so far as possible the carbon was heated to a temperature not much below that at which it would have begun to burn and was then burned in a little platinum boat in a stream of carefully purified and well-dried oxygen. One specimen gave absolutely no water, showing the absence both of water vapor and of combined hydrogen. Unfortunately, these experiments were not carried further, so we know nothing about the properties of this charcoal.

Mixter" calls attention to the fact that the difficulty in obtaining amorphous charcoal fairly pure is a serious obstacle in a study of its properties. It is usually stated that the hydrogen may be removed by heating charcoal in chlorine; but Mixter was unable to find out who was the authority for this statement or what analytical tests have been used to show

1 Porcher: Chem. News, 44, 203 (I88r).

${ }^{2}$ Am. Jour. Sci., [3] 45, 363 (I 893 ). 
whether the resulting product was free from chlorine. Berthelot and Petit ${ }^{1}$ treated wood charcoal with hydrofluoric and hydrochloric acids, then with chlorine at a red heat, and finally calcined it in a Perrot furnace, which probably removed all the chlorine. When Weber $^{2}$ was determining the specific heat of carbon, he prepared amorphous carbon by heating wood charcoal to bright redness for fifteen minutes in a stream of chlorine in order to remove hydrogen; but he does not say how he proved the absence of chlorine. Wright and Luff $^{3}$ heated sugar charcoal for two hours in chlorine and then ignited it for six hours in platinum over a blow-pipe to remove chlorine. Two analyses gave the following results:

\begin{tabular}{l|r|r}
\hline \hline Carbon & 96.17 & 95.13 \\
Hydrogen & 0.84 & 0.75 \\
Ash & I.56 & I.68 \\
Oxygen (by difference) & I.43 & 2.44
\end{tabular}

These analyses are interesting as showing how tenaciously charcoal retains hydrogen even after ignition in chlorine.

While attempting to prepare amorphous carbon free from hydrogen, Mixter observed that charcoal retains some chlorine even at high temperatures. He worked with carbon black, sugar charcoal, and gas carbon. The sugar charcoal contained $0.13 \%$ hydrogen and $0.04 \%$ ash. It burned with difficulty in oxygen, was hard enough to scratch glass, and was a good conductor of electricity. The carbon black was made from natural gas; $;^{4}$ it contained $1.0 \%$ hydrogen, and $0.04 \%$ ash. An air-dry specimen showed $0.23 \%$ nitrogen by the absolute method. After the carbon black had been ignited for two hours in dry nitrogen and then allowed to cool in the gas, no nitrogen was obtained on burning with copper oxide. This kind of carbon black conducts electricity when pressed into compact pieces. When heated in a vacuum it yields a

\footnotetext{
' Bull. Soc. chim. Paris, [3] 2, 90 (I889).

2 Phil. Mag., [4] 49, I6I, 276 (I875).

${ }^{5}$ Jour. Chem. Soc., 33, 17 (1878).

${ }^{4}$ Mallet: Chem. News, 38, 94 (1878).
} 
small sublimate. The gas carbon was the intier portion of a thick piece. It contained $0.035 \%$ hydrogen and $0.88 \%$ ash.

The gas carbon did not take up chlorine when heated with it, whereas the sugar charcoal and the carbon black, which contain more hydrogen, retain some chlorine persistently, apparently because the chlorine has reacted with the hydrocarbons in the charcoal. While carbon black does not retain nitrogen when heated with this gas, it does when heated with ammonia or with oxides of nitrogen. Mixter assumes that these gases decompose and that the nascent nitrogen reacts with the charcoal. It is not known what the product is, but it cannot be paracyanogen because this would be converted into cyanogen at high temperatures.

Since charcoals may contain graphite, it is necessary to have some definition and test of this substance. Berthelot defines as graphite any sort of carbon which yield graphitic oxide on oxidation. ${ }^{1}$ The best oxidizing medium is a mixture of potassium chlorate and nitric acid. The higher the temperature at which the graphite has been formed, the less readily it is attacked by the mixture. Certain graphites swell when oxidized. This is due apparently to the sudden evolution of gas between the plates. While the characteristic reaction of graphitic oxide is extraordinarily sharp with lamellar, natural graphite, ${ }^{2}$ it is difficult to apply with the very fine, pulverulent charcoal obtained by certain reactions in the laboratory. Graphitic oxide is absolutely insoluble and keeps the special form of the oxidized carbon. With natural graphite one gets yellow plates of fair size which settle rapidly in water and in salt solutions. It can be recognized easily. With very finely divided charcoals, it comes down as an inpalpable dust, scarcely yellowish, which stays suspended for a long time in liquids. Precipitation and washing by decantation require many precautions and much time. The graphitic oxide thus obtained can be recognized by its property of deflagrating

\footnotetext{
${ }^{1}$ Moissan: Ann. Chim. Phys., [7] 8, 306 (1896).

${ }^{2}$ Le Chatelier and Wologdine: Comptes rendus, 146, 49 (1908); I48, r715 (r909).
} 
when heated, forming a black, voluminous mass of pyrographitic oxide.

The densities of graphites, as determined by flotation in mixed liquids vary from $\mathrm{r} .62$ to 2.44 , depending on the source of the graphite. When purified carefully, the values all come out practically $2.255,15 \% 4^{\circ}$. There is, therefore, only one graphite. Le Chatelier and Wologdine consider that there is also only one amorphous carbon with a density of about I.8. Mixter found I.919 for the carbon obtained by the explosion of acetylene under pressure; but this probably contained some graphite because Le Chatelier and Wologdine state that acetylene black containing graphite will give $2.05^{-}$ 2.I 5 .

The so-called graphitite from Wunsiedel in the Fichtel. gebirge, has always been looked upon as amorphous, ${ }^{1}$ and Luzi has made further examination as to whether this is really correct. He finds that the mineral consists of pure carbon containing neither hydrogen nor nitrogen; microscopic examination shows no signs whatever of the substance being of crystalline nature. The conclusion arrived at is that this form of carbon is amorphous, but that it differs considerably from wood charcoal, for ordinary amorphous charcoal has a sp. gr. 1.57-1.88 while the graphitite in question has the sp. gr. 2.21-2.26 (Ceylon graphite according to Brodie has the sp. gr. 2.25-2.26); again, ordinary amorphous carbon is completely oxidized by potassium chlorate and red fuming nitric acid, without formation of the slightest trace of insoluble graphitic acid, while amorphous graphitite gives an insoluble crystalline oxidation product perfectly analogous to or identical with that obtained from crystalline graphite. Schungite occurring in Russia cannot well be compared with the above, since it contains 0.5 percent of hydrogen and 0.5 percent of nitrogen, but it agrees well with ordinary amorphous carbon in that it has about the same specific gravity and in that on oxidation it yields no graphitic acid.

Animal charcoal is usually bone charcoal though it may

${ }^{1}$ Luzi: Ber. deutsch, chem. Ges., 25, 1378 (1892). 
be made from dried blood, flesh, horns or leather. It should be made from well-selected clean bones of compact structure. ${ }^{1}$ These are crushed and then treated with a solvent such as petroleum naphtha to remove the fat and they are then carbonized in cast-iron retorts. Charring for IO-I 2 hours at a red heat gives better results than charring at a higher temperature for 6-8 hours. A cherry-red heat is the best for producing a black charcoal. At lower temperatures the decomposition of the organic matter is not complete and the product has a characteristic reddish brown color. Too high a temperature gives rise to a vitreous charcoal which generally has a bluish tinge. It is important that the temperature should be kept low in the initial stage of the process, until all of the water has been drawn off, after which it is raised gradually to a cherry-red glow. The charcoal is removed from the retorts and cooled in closed iron vessels. When the charcoal is cold, it is crushed to the desired size. In Austria charcoal is used in lumps the size of a walnut; in Germany the lumps. are no larger than a hazel nut, while the French crush to granules of the size of linseed, and in England and America millet seed is the standard. ${ }^{2}$

In new charcoal the carbon should range from 9 to II.5 percent, the siliceous matter should not exceed 0.5 percent, the ferric oxide 0.15 percent, and the calcium sulphate 0.2 percent. The balance is chiefly calcium phosphate. The color should be black or dark brown. The charcoal should be hard but also porous and should adhere strongly to the tongue. Charcoal made from dried blood, etc., is usually too friable for use in sugar refining; but is used to some extent in bleaching oils, fats, glycerine, etc. Unless dried, bone black may easily contain ten percent water. Bone black always contains nitrogen; but this is not usually given in the analyses. Wallace ${ }^{3}$ found $\mathrm{I} .55$ percent in a total of 8.5 of so-called carbonaceous matter in char made from home-collected bones, but in another

\footnotetext{
${ }^{1}$ Newlands and Newlands: Jour. Soc. Chem. Ind., 7, 419 (1886).

'Zapiski: Jour. Soc. Chem. Ind., I2, 532 (1893).

${ }^{3}$ Chem. News, I7, 249 (1868).
} 
sample made from foreign bones it was 1.08 out of 9 parts of carbonaceous matter. It diminishes in quantity as the char is used. Two samples of moderately old charcoal gave, respectively, 0.3 and 0.55 percent nitrogen, while the carbon was reported at 15 and 17 percent, respectively.

When the fatty matter in uncharred bones is extracted with ether and the mineral matter with hydrochloric acid, there remains a semi-transparent substance of somewhat variable composition - called ossein. When treated with hot water it is converted into gelatin. The mean value of the analyses of all the bones comprising the skeleton of an ox are ossein 24 percent and ash 66 percent. The large bones such as the femur are the richest in ossein and, therefore, the best for the manufacture of charcoal. Bones which have been exposed to the atmosphere or to moisture lose their ossein and yield a charcoal of little value, which may be recognized by its gray color.

Glassner and Suida ${ }^{1}$ give the following analyses of various charcoals.

Water content refers to air-dried charcoal, the other figures to charcoals dried to constant weight at $110^{\circ}$.

\begin{tabular}{|c|c|c|c|c|c|c|}
\hline & Water & C & $\mathrm{H}$ & $\mathrm{N}$ & $\begin{array}{l}\mathrm{O}(\mathrm{S}) \\
\text { about }\end{array}$ & Ash \\
\hline Animal charcoal & 8.29 & 78.03 & 0.4 & 3.02 & $5 \cdot 34$ & $13.2 \mathrm{I}$ \\
\hline Blood charcoal & $25 \cdot 99$ & $69 \cdot 98$ & $\mathrm{I} \cdot 7^{2}$ & $7 \cdot 19$ & $14.7 \mathrm{I}$ & 6.4 \\
\hline Bone charcoal & I 7.95 & 67.12 & I . 24 & 6.9 & $20.5^{8}$ & $4 \cdot 16$ \\
\hline Glue charcoal & 4.86 & 63.61 & 2.25 & $\mathrm{I} 2.2 \mathrm{I}$ & $9 \cdot 43$ & I 2.5 \\
\hline Soot & 3.87 & 92.06 & 0.73 & - & $7.2 \mathrm{I}$ & - \\
\hline Soot I & - & 91.70 & $0.7 \mathrm{I}$ & 一 & $75 \cdot 9$ & - \\
\hline Soot II & 一 & 93.67 & $0.5 \mathrm{r}$ & - & 5.82 & - \\
\hline Wood charcoal & 3.83 & 61.17 & $2 \cdot 55$ & Trace & 34.05 & 2.23 \\
\hline Sugar charcoal & 3.99 & $78.9 \mathrm{I}$ & 0.79 & - & 20.30 & - \\
\hline Acetylene black & - & 98.98 & O. I I & - & $0.9 \mathbf{I}$ & - \\
\hline
\end{tabular}

Patterson" gives analyses of a series of typical charcoals used in sugar refining.

${ }^{1}$ Liebig's Ann., 357, 101 (1907); 361, 354 (1908).

${ }^{2}$ Jour. Soc. Chem. Ind., 22, 612 (1903). 
Anai,yses of Charcoals

\begin{tabular}{|c|c|c|c|c|}
\hline & I & II & III & IV \\
\hline $\begin{array}{l}\text { Carbonaceous matter........ } \\
\text { Organic matter soluble in }\end{array}$ & I 8.22 & I 4.47 & 8.84 & $9 \cdot 72$ \\
\hline $\begin{array}{c}\mathrm{H}_{2} \mathrm{SO}_{4} \ldots \ldots \ldots \ldots \ldots \ldots \\
\text { Organic matter soluble in }\end{array}$ & I. 97 & 2.09 & 1.90 & I. 70 \\
\hline $\begin{array}{l}\mathrm{HCl} \ldots \ldots \ldots \ldots \ldots \ldots \ldots \\
\text { Organic matter soluble in }\end{array}$ & I .37 & I. 59 & I. 33 & I. 46 \\
\hline $\begin{array}{l}\text { water. } \\
\mathrm{CO}_{2} \text { lost on ignition } \ldots \ldots \ldots \\
\text { Ash } \ldots \ldots \ldots \ldots \ldots\end{array}$ & $\begin{array}{r}0.44 \\
2.00 \\
76.00\end{array}$ & $\begin{array}{r}0.43 \\
2.96 \\
78.46\end{array}$ & $\begin{array}{r}0.12 \\
3.02 \\
84.79\end{array}$ & $\begin{array}{r}0.28 \\
2.98 \\
83.86\end{array}$ \\
\hline & IOO. ÓO & 100.00 & 100.00 & 100.00 \\
\hline $\begin{array}{l}\text { Total } \mathrm{CO}_{2} \ldots \ldots \ldots \ldots \ldots \ldots \\
\mathrm{N} \text { in carbonaceous and }\end{array}$ & 2.48 & $3 \cdot 50$ & $3 \cdot 53$ & $3 \cdot 16$ \\
\hline $\begin{array}{l}\mathrm{H}_{2} \mathrm{SO}_{4} \text { organic matter.... } \\
\mathrm{N} \text { in } \mathrm{HCl} \text { and } \mathrm{H}_{2} \mathrm{O} \text { organic }\end{array}$ & I. 85 & I. 75 & 0.99 & 0.84 \\
\hline 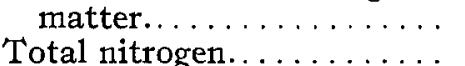 & $0.5 \mathrm{I}$ & 0.33 & O. IO & 0.26 \\
\hline
\end{tabular}

\begin{tabular}{|c|c|c|c|c|c|}
\hline & $\mathrm{V}$ & VI & VII & VIII & IX \\
\hline \multicolumn{6}{|l|}{$\begin{array}{l}\text { Carbonaceous mat- } \\
\text { ter.......... }\end{array}$} \\
\hline $\begin{array}{l}\text { Organic matter sol- } \\
\text { uble in } \mathrm{H}_{2} \mathrm{SO}_{4} \ldots \ldots \\
\text { Organic matter sol- }\end{array}$ & 0.27 & 0.29 & 0.40 & 0.02 & 0.04 \\
\hline $\begin{array}{l}\text { uble in } \mathrm{HCl} . . . \\
\text { Organic matter sol- }\end{array}$ & 0.55 & I. 06 & 0.97 & 一 & - \\
\hline uble in water... & 0.56 & 一 & 一 & 一 & 一 \\
\hline $\begin{array}{l}\mathrm{CO}_{2} \text { lost on ignition. } \\
\mathrm{Ash} \ldots \ldots \ldots \ldots \ldots\end{array}$ & $\begin{array}{r}2.12 \\
86.37\end{array}$ & $\begin{array}{r}1.77 \\
8=-2\end{array}$ & I . I I & $\overline{0.02}$ & $\begin{array}{r}0.07 \\
82.82\end{array}$ \\
\hline \multirow{2}{*}{ Ash $\ldots \ldots \ldots \ldots$} & 86.37 & $85 \cdot 5^{2}$ & 81.27 & 95.03 & 02.02 \\
\hline & 100.00 & 100.00 & 100.00 & 100.00 & 100.00 \\
\hline $\begin{array}{l}\text { Total } \mathrm{CO}_{2} \ldots \ldots \ldots \\
\mathrm{N} \text { in carbonaceous } \\
\text { and } \mathrm{H}_{2} \mathrm{SO}_{4} \text { organic }\end{array}$ & 2.45 & 2.07 & I. $6 \mathrm{I}$ & 0.09 & 0.25 \\
\hline $\mathrm{N}$ in $\mathrm{HCl}$ and $\mathrm{H}_{2} \mathrm{O}$ & 0.55 & 0.67 & $0.7 \mathrm{I}$ & 一 & - \\
\hline organic matter... & - & o. I 8 & 0.07 & - & - \\
\hline Total nitrogen.... & - & 0.85 & 0.78 & o. I 5 & $\cdot 0.66$ \\
\hline
\end{tabular}

No. $I$ is the dust from new charcoal. Nos. II, III, IV, and V are new charcoals. No. VI is refinery stock charcoal which has 
been 8 weeks in use. No. VII is refinery stock charcoal which has been in use for 35 weeks. Nos. VIII and IX are spent charcoals turned out of refineries as useless.

A great difference is noticeable in the percentage of carbonaceous matter in these charcoals. I and II have been made from bones from which little, if any, of the gelatine was boiled out before charring, like III, IV, and V. VI and VII are stock charcoals from one refinery where the carbonaceous matter increases with use, by the charring of vegetable matter absorbed from the sugar solutions in the process of revivification. In VIII the carbonaceous matter had been reduced to about half that in new charcoal by air leakages in the same process; and No. IX, like No. VII, has accumulated carbon, to the extent of about $7^{1 / 2}$ percent in the course of long use.

The organic matter soluble in water is a trifling quantity, but it is present in all new charcoals. Of course the first washing removes it.

The organic matter soluble in sulphuric acid is a significant constituent of animal charcoal. Together with the carbonaceous matter it forms the residue obtained on treatment with hydrochloric acid, usually called carbon. No. V, which only contains 0.27 percent, has been charred at a higher temperature, and probably for a longer period than the other four new charcoals. The refinery stock charcoals, VI and VII, have lost a large portion of this organic matter, and the spent charcoals, VIII and IX, contain little more than a trace. This organic matter probably plays an important part in the life of the charcoal. The organic matter soluble in hydrochloric acid, although a different quantity and probably containing a little water, is also a significant constituent.

Bone black is used to remove coloring matter and lime salts from sugar. It also takes out gummy matters and, unfortunately, adsorbs a certain amount of sugar. ${ }^{1}$

"In refining sugar, a hot solution of a density of about $50^{\circ} \mathrm{Brix}$ is passed through filter presses or bag filters, and then

' Clark: Jour. Soc. Chem. Ind., 32, 262 (1913). 
slowly run on to animal charcoal, contained in cisterns about $20 \mathrm{ft}$. high and $8 \mathrm{ft}$. in diameter and holding about 30 tons. For 20 to 40 hours the liquid percolates through the charcoal, after which hot water is turned on to wash out all the sweet matters. The absorbent properties of the successive layers of charcoal brought into play, the upper portions becoming soon saturated with impurities, while the lower portions only become charged after a considerable time. The liquor which runs off at first, is quite colorless and serves for the manufacture of the highest quality of white sugar. In the course of a few hours it becomes slightly yellowish, and as filtration proceeds, there is a gradual increase in color intensity, until at the end of the operation, it is of a more or less brownish yellow color and can only be utilized for making lower qualities of refined sugars. About one ton of charcoal is used per ton of sugar. Without a well-purified sugar liquor, a large yield of the best quality of white sugar cannot be obtained from the massecuite, owing to the loss of sugar cyrstals in the centrifugal machines from the subsequent excessive washing with water which is necessary to remove adhering colored syrup. The decolorizing power of the charcoal is more or less affected by the nature of the impurities present in raw cane sugars, and it is a matter of common experience that sugars having practically the same polarizations are not equally serviceable from a refining point of view. This may be due to the variety of sugar cane crushed, the soil on which the cane has been grown, or to the process of manufacture of the raw sugar."

Given two sugar solutions of the same color intensity but one containing more salts and more invert sugar, bone black will decolorize the solution with the lesser quantity of salts and invert sugar more effectively than the other. A solution of raw sugar, having a certain color intensity but with a low content of invert sugar and salts may have $95 \%$ of its color abstracted by boneblack while another raw sugar solution of approximately the same color but containing more invert sugar and salts may show no more than $85 \%$ decolorization after contact with charcoal. 
In time the bone black ceases to be active, owing to the accumulation of lime salts and of organic matter. It can be revivified by igniting and treating with acid or in other ways. The general question of revivification will be discussed in detail later; but now it is necessary to consider what factors affect the adsorption by bone black.

As has been pointed out, the so-called carbon in animal charcoal is not pure carbon but consists of a series of complex organic compounds containing a large percentage of nitrogen. The calcium phosphate is not the important ingredient in the decolorizing because the char loses practically all power of removing coloring matter ${ }^{1}$ if it is burned perfectly white. If the calcium phosphate be removed, ${ }^{2}$ the residual char decolorizes more effectively than the original char. Thus it was found by experiment that the decolorizing effect of the carbon from Iooo grams of old char was greater than that of the entire weight of the char from which it was obtained. It is not practicable, however, to use in sugar refining a charcoal from which the calcium phosphate has been removed because the product is too soft and because it sinters too much when reburned. It is apparently agreed that the main part played by the calcium phosphate is to give the proper structure and rigidity to the charcoal. This does not mean that calcium phosphate has no adsorbing powers. Stenhouse ${ }^{3}$ found that the decolorizing power of wood charcoal was increased by impregnation with calcium phosphate and it seems probable from his data that this is a specific effect. It is worth noting, however, that the maximum beneficial effect was obtained with only 7.5 percent calcium phosphate which is a very different value from that for bone black. This point will be discussed later.

In view of the fact that ordinary wood charcoals, which contain no nitrogenous compounds, are very poor decolorizers,

1 Wallace: Chem. News, I7, 249 (I868).

2 Newlands and Newlands: Jour. Soc. Chem. Ind., 7, 429 (1888).

${ }^{3}$ Liebig's Ann., Ior, 243 (1856). 
Patterson ${ }^{1}$ believes that the efficiency of bone black is due in large part to the presence of nitrogenous compounds and he attempts to prove it by extracting this material with hydrochloric acid and sulphuric acid, and observing its properties. The organic compounds extracted by boiling sulphuric acid were precipitated with water and tested against a standard caramel solution. Weight for weight their decolorizing action was 16-40 times as much as that of a good bone black. The substance extracted by cold sulphuric acid was sixteen times as effective as equal weight of bone black. There is, therefore, no question but that the nitrogenous compounds may be the effective decolorizing agents though it does not follow that they must always be.

In order to get more information as to these organic compounds, Patterson ${ }^{2}$ treated a large portion of charcoal dust with hydrochloric acid solution, washed by decantation, and dried thoroughly. "The dried carbonaceous residue from the hydrochloric acid treatment was further digested with cold sulphuric acid to separate the organic matter. The acid filtrate was poured into water, and the precipitated organic matter washed by decantation, and finally collected on a filter, scraped into a porcelain basin, and dried. The operation is tedious, but 2 to 3 grams of the organic body were finally obtained. In the process of washing to obtain the pure body it was noticed that after five washings by decantation the precipitate would not settle, but remained in suspension or in colloidal solution in the next washing water and sulphuric acid had to be added to throw it down again. Washing with water on the filter does not dissolve the precipitate when the acid is removed, although it carries it through mechanically if stirred up in doing so; but the organic matter separated by sulphuric acid at $100^{\circ} \mathrm{C}$ goes freely into colloidal solution on the filter as the acid is washed out and separates again after long standing.

"In the dry condition the organic body presents a horny

${ }^{1}$ Jour. Soc. Chem. Ind., 22, 608 (1903).

2 Ibid., 22, 6 10 (1903). 
appearance with conchoidal fracture. Heated in a test-tube it chars very easily, giving off whitish yellow vapors with a strong smell of burnt bones. Thrown into water it does not again assume the hydrated condition. It is insoluble in water, cold or hot; and insoluble in alcohol, ether, benzene, and chloroform. It dissolves freely in sulphuric acid, from which it is thrown down by water in the gelatinous condition, but the acid solution has a reddish color, not yellow like the dilute acid filtrate from the first sulphuric acid separation, which indicates some slight change due to the treatment. Concentrated hydrochloric acid dissolves the hydrated body in the cold to a brown solution. Boiling makes little difference. Dilution with water throws it down again, from which a filtrate is obtained with a very slight yellow color. Boiled with concentrated nitric acid, free from nitrous acid, the body dissolves with liberation of a little nitrous acid, to a brown solution. On dilution with water a portion of the substance precipitates, leaving the solution yellow. The addition of ammonia does not increase the color of the filtrate, as it would if proteids were present. Neither does Millon's test give any reaction for these bodies. Glacial acetic and citric acids have very little action. Tannin does not produce any precipitate in the colloidal solution referred to above, but aluminium, iron, copper, mercury, and magnesium salts do. They do not precipitate the dilute sulphuric acid solution, perhaps because so little substance is present. Strong ammonia dissolves the hydrate freely and dilution does not precipitate it, but it falls out partially on heating, leaving a yellow solution which deposits a few yellow needle-like crystals when evaporated to dryness. This reaction points to the body having the properties of an acid in very dilute solution, while it has those of a base in the original charcoal.

"The dried organic body is only very slightly soluble in strong ammonia, but ammonia does not separate any of it from the carbonaceous residue of charcoal. It is insoluble in soda solution. It neither contains sulphur nor ash. A $5^{\circ}$ percent solution of sugar shaken with the dried organic 
body dissolves a very little to a brownish color which remains brownish when diluted.

"The following results were obtained on analysis of the organic body: I. $0.2262 \mathrm{~g}$ gave $0.5217 \mathrm{~g} \mathrm{CO}_{2}$ and $0.086 \mathrm{I} \mathrm{g}$ $\mathrm{H}_{2} \mathrm{O}$. II. $0.2024 \mathrm{~g}$ gave $0.473^{8} \mathrm{~g} \mathrm{CO}_{2}$ and $0.0797 \mathrm{~g} \mathrm{H}_{2} \mathrm{O}$; and by the Kjeldahl process: I. $0.5262 \mathrm{~g}$ gave $\mathrm{NH}_{3}=$ 4.485 cc normal $\mathrm{H}_{2} \mathrm{SO}_{4}$ solution. II. $0.4866 \mathrm{~g}$ gave $\mathrm{NH}_{3}=$ 4. I60 cc normal $\mathrm{H}_{2} \mathrm{SO}_{4}$ solution. Worked out, these figures give the following percentages:

\begin{tabular}{|c|c|c|c|}
\hline & \multicolumn{2}{|c|}{ Experiment } & \multirow{2}{*}{$\begin{array}{l}\text { Ox-bone } \\
\text { Cartilage }\end{array}$} \\
\hline & I & II & \\
\hline Carbon. & 62.90 & 63.26 & $49.8 \mathrm{I}$ \\
\hline Hydrogen. & 4.23 & $4 \cdot 37$ & $7 \cdot 14$ \\
\hline Nitrogen . . . . . . . . . & I I . 98 & I I. 97 & $17 \cdot 3^{2}$ \\
\hline \multirow[t]{2}{*}{ 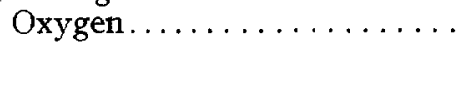 } & 20.89 & 20.40 & 25.67 \\
\hline & 100.00 & 100.00 & $99 \cdot 94$ \\
\hline
\end{tabular}

"These results correspond with the empirical formula $\mathrm{C}_{25} \mathrm{H}_{20} \mathrm{~N}_{4} \mathrm{O}_{6}$. The decomposition and oxidation products have not yet been studied. But since we know the body itself to be a decomposition product of bone cartilage, I have put alongside an analysis of the latter by Frémy ${ }^{1}$ for comparison. It is apparent from this analysis that decomposition has not proceeded far, or at any rate so far as we might expect, when we recollect that the bones must have been submitted to a red heat for at least 12 hours in reducing them to charcoal. The large percentage of oxygen, which with its equivalent of hydrogen from the elements of 23 percent of water, might lead us to infer that this substance is a product of the action of the sulphuric acid on the carbonaceous matter, or that it is due to the organic body holding added water so tenaciously that a temperature of $100^{\circ} \mathrm{C}$ is incapable of drying it. Had the action been the result of oxidation or hydrolysis the weight of the organic body would have been considerably increased,

1 Watt's Dictionary, $\mathrm{I}, 620$ 
and the analysis of the carbonaceous residue from hydrochloric acid, given above, would have shown this. But the three constituents of that residue were estimated directly, and they total rather under Ioo. We have seen that no heat is developed and no gas liberated when this residue is treated with sulphuric acid, as would have been the case had the acid acted chemically on it, and had it contained uncombined water. Much heat is liberated when the residue is not dry from the combination of the acid with the water present. The action seems to be a simple case of dissolution on the part of the acid. We must, therefore, conclude that the oxygen is a constituent element of the organic body, and that it exists in the charcoal itself, as it does in the bone cartilage. I am not aware that oxygen has previously been observed as a constituent of charcoal, but its presence accounts for the fact that water can be driven off at all temperatures up to $300^{\circ} \mathrm{C}$. Clark $^{1}$ objects to the theory that the decolorizing power of bone black is due chiefly to nitrogenous organic compounds or to "complex nitrogenous carbon" because bone black reaches its maximum decolorizing power only after repeated washings and reburnings, when much of the nitrogen combined with organic matter disappears. It seems to him that the maximum decolorizing power should be exerted when nitrogenous organic compounds were present in large excess. This objection would be sound if it were a question of solution; but the state of the surface is very important in the case of adsorption and it is probable that a given bone black will give the best results with a definite amount of nitrogenous matter, and this concentration need not necessarily be that which occurs fortuitously in freshly-burned charcoal. On the other hand there seems to be good reason to believe that a wood charcoal can be made having a higher decolorizing power than most animal charcoals and perhaps higher than any animal charcoal, so that nitrogenous compounds are not necessary though they may be desirable. Since adsorption is specific, we must distinguish two factors, the nature and the structure of the sur-

${ }^{1}$ Jour. Soc. Chem. Ind., 32, 262 (I9I3). 
face. If a given surface will not take up a dissolved or dispersed substance, we can get results by impregnating with a third substance which is adsorbed strongly by the surface and adsorbs the dissolved or dispersed substance. Cotton adsorbs certain coloring matters so slightly that it cannot be dyed with them. Dyeing can be effected by mordanting cotton with alumina or tannin as the case may be. The adsorption by wool is so much greater in many cases that a mordant is not necessary though one may be used. The difference between wool and cotton may be realized in charcoal by unspecified changes in the structure. We can consider the nitrogenous compounds as mordants for the coloring matter in sugar. If we have a charcoal of low adsorbing power, the presence of the nitrogenous matter in suitable amount will increase the adsorption very much. If we have a charcoal with just the right structure for adsorbing a particular coloring matter, the addition of nitrogenous matter may clog the pores or disturb things otherwise so as to be positively detrimenta! On this hypothesis it is easy to see why people working with different charcoals may get apparently contradictory results. The-e has been no way of making quantitative comparisons between structures and consequently this factor has only been tecognized to a minor extent. People have realized that the porosity of the charcoal was important; but they have not asked themselves what was the proper size or shape of pores to give the best results.

Cornell University 